\title{
Weill-Marchesani syndrome in three generations
}

\begin{abstract}
Background Weill-Marchesani syndrome is a rare systemic connective tissue disorder consisting of brachymorphy, brachydactyly, ectopia lentis, spherophakia and glaucoma. Methods We report 6 patients with Weill-Marchesani syndrome (with or without ocular involvement) in three generations, identified by screening 26 members of two families. This is the largest family in the literature showing an autosomal dominant pattern of inheritance. Results Presenile vitreous liquefaction was present in all the younger cases. WeillMarchesani syndrome was full-blown in two cases in the third generation, in which asymmetrical axial length and glaucomatous damage were present. To our knowledge this is the first report regarding asymmetrical axial length and glaucomatous damage, and presenile vitreous liquefaction in WeillMarchesani syndrome with or without ocular involvement.

Conclusions The longer axial length might be the precursor of impending severe glaucomatous damage. Presenile vitreous liquefaction in subtle young cases should alert the physician to the diagnosis of WeillMarchesani syndrome on screening of the family members.
\end{abstract}

Key words Weill-Marchesani, Dominant, Vitreous liquefaction, Glaucoma

Weill-Marchesani syndrome was first reported by Weill ${ }^{1}$ and Marchesani ${ }^{2}$ and is considerably less common than Marfan syndrome and homocystinuria. ${ }^{3}$ Both autosomal recessive and dominant inheritance have been described. ${ }^{46}$ In this study we present 6 cases with Weill-Marchesani syndrome in three generations. To our knowledge, this is the largest family described in the English literature. Asymmetrical axial length and glaucomatous damage were present in two fullblown cases; these signs have not been reported in the literature. Vitreous liquefaction was present in all cases.
Case reports (Table 1)

Case 1 (Fig. 1, III-3)

A 27-year-old white woman was admitted to our outpatient clinic with a complaint of headache and strabismus. She denied any medication in the past, and past medical history was normal. She was prescribed a myopic spectacles of $-8.0 \mathrm{D}$ bilaterally. The best corrected visual acuity with a $-12.0 \mathrm{D}$ sphere was $6 / 30$ in the right eye and no light perception in the left eye. She also had an exodeviation of 50 prism dioptres in the left eye. The corneas were clear with an estimated size of $11.7 \mathrm{~mm}$ in both eyes horizontally.

Iridophacodonesis was present bilaterally and the pupils were in a central position. Vitreous liquefaction was present in both eyes. The intraocular pressures (IOP) by applanation were 35 and $19 \mathrm{mmHg}$ in the right and left eye in the morning, respectively. Perimetry could not be obtained pre-operatively in the right eye. In gonioscopic examination with a Goldmann triple-mirror lens the peripheral iris was in contact with the trabeculum behind Schwalbe's line in all quadrants with a minute part of the open trabecular meshwork with a

hyperpigmented appearance bilaterally. After pupillary dilation, the entire circumference of the microspherophakic lenses was visible and they were seen to be subluxated inferomedially in both eyes. Zinn's zonules were defective superolaterally in both eyes. The equatorial diameter of the lenses was measured in projected slides from photographs of the anterior segment of the eyes with dilated pupils. Lensectomy was performed in the right eye. Post-operatively, the best corrected visual acuity with $+11.0 \mathrm{D}$ sphere was $6 / 7.5$ and perimetry was normal.

The patient was $144 \mathrm{~cm}$ tall ( $<3 \mathrm{rd}$ percentile) with a weight of $54.5 \mathrm{~kg}$ ( $25 \mathrm{th}$ percentile). In addition to clumsy feet with short toes, the fingers were short and stubby with a palmar length of $8.5 \mathrm{~cm}$. Physical examination revealed a normal head circumference measuring $55 \mathrm{~cm}$. Radiography showed brachymetacarpia, especially prominent in the first and fifth metacarpals. Flexion and extension limitation at the wrist were present $\left(10^{\circ}\right.$ and $20^{\circ}$ respectively). General examination was otherwise within the normal limits.
C. Evereklioglu

I.F. Hepsen

H. Er

Department of

Ophthalmology

Turgut Özal Medical Centre Inönü University

Malatya, Turkey

Dr Cem Evereklioglu Sivas Cad. Cebeci Apt. A-Blok: 175/15

38020, Kayseri, Turkey

Tel: +90 5324172841 Fax: +904223410619 e-mail:

evereklioglu@hotmail.com

Received: 24 February 1999 Accepted in revised form: 4 August 1999 


\begin{tabular}{|c|c|c|c|c|c|c|c|c|c|c|c|c|}
\hline & \multicolumn{2}{|c|}{ Case II-5 } & \multicolumn{2}{|c|}{ Case III-3 } & \multicolumn{2}{|c|}{ Case III-6 } & \multicolumn{2}{|c|}{ Case IV-1 } & \multicolumn{2}{|c|}{ Case IV-2 } & \multicolumn{2}{|c|}{ Case IV-3 } \\
\hline \multicolumn{13}{|l|}{ Systemic findings } \\
\hline Age (years) & \multicolumn{2}{|c|}{65} & \multicolumn{2}{|c|}{27} & \multicolumn{2}{|c|}{19} & \multicolumn{2}{|c|}{8} & \multicolumn{2}{|c|}{5} & \multicolumn{2}{|c|}{3} \\
\hline Sex & \multicolumn{2}{|c|}{$\mathrm{F}$} & \multicolumn{2}{|c|}{$\mathrm{F}$} & \multicolumn{2}{|c|}{$\mathrm{M}$} & \multicolumn{2}{|c|}{$\mathrm{F}$} & \multicolumn{2}{|c|}{$\mathrm{M}$} & \multicolumn{2}{|c|}{$\mathrm{F}$} \\
\hline Height $(\mathrm{cm})$ & \multicolumn{2}{|c|}{$141\left(<3^{\text {rd }}\right)$} & \multicolumn{2}{|c|}{$144\left(<3^{\text {rd }}\right)$} & \multicolumn{2}{|c|}{$152\left(<3^{\text {rd }}\right)$} & \multicolumn{2}{|c|}{$110\left(<3^{\text {rd }}\right)$} & \multicolumn{2}{|c|}{$98\left(3^{\text {rd }}\right)$} & \multicolumn{2}{|c|}{$85\left(<3^{\text {rd }}\right)$} \\
\hline Weight $(\mathrm{kg})$ & \multicolumn{2}{|c|}{55} & \multicolumn{2}{|c|}{54.5} & \multicolumn{2}{|c|}{52} & \multicolumn{2}{|c|}{19.5} & \multicolumn{2}{|c|}{16.9} & \multicolumn{2}{|c|}{12.9} \\
\hline Articular restriction & \multirow{2}{*}{\multicolumn{2}{|c|}{$\begin{array}{l}+ \\
+\end{array}$}} & + & & - & & & & & & & \\
\hline Brachydactyly & & & + & & - & & & & & & & \\
\hline Ocular findings & OD & OS & OD & OS & OD & OS & OD & OS & OD & OS & OD & OS \\
\hline Visual acuity & $6 / 6$ & $6 / 6$ & $6 / 7.5$ & P- & $6 / 10$ & HM & $6 / 6$ & $6 / 6$ & $6 / 6$ & $6 / 6$ & $6 / 6$ & $6 / 6$ \\
\hline Myopia & - & - & $-12 \mathrm{D}$ & $-12 \mathrm{D}$ & $-7.5 \mathrm{D}$ & $-7.5 \mathrm{D}$ & - & - & - & - & - & - \\
\hline Axial length $(\mathrm{mm})$ & 22.17 & 22.15 & 21.23 & 22.54 & 20.40 & 21.72 & 22.54 & 22.58 & 21.71 & 21.44 & 21.68 & 21.31 \\
\hline Iridophacodonesis & - & - & + & + & + & + & - & - & - & - & - & - \\
\hline Lens & & & & & & & & & & & & \\
\hline Subluxation/position & $\mathrm{C}$ & C & IM & IM & I & SM & C & C & C & C & C & $\mathrm{C}$ \\
\hline Sagittal diameter $(\mathrm{mm})$ & 4.50 & 4.50 & 5.11 & 5.11 & 5.00 & 5.00 & 3.36 & 3.38 & 3.90 & 3.82 & 3.80 & 3.81 \\
\hline Equatorial diameter $(\mathrm{mm})$ & 8.0 & 8.0 & 7.8 & 7.8 & 7.7 & 7.7 & 8.5 & 8.5 & 8.2 & 8.2 & 7.7 & 7.7 \\
\hline Intraocular pressure $(\mathrm{mmHg})$ & 14 & 15 & 35 & 19 & 18 & 41 & 16 & 14 & 12 & 13 & 13 & 13 \\
\hline Fundus & & & & & & & & & & & & \\
\hline Optic disc disappearance & $\mathrm{N}$ & $\mathrm{N}$ & $\mathrm{N}$ & $\mathrm{A} / \mathrm{E}$ & $\mathrm{N}$ & $\mathrm{A} / \mathrm{E}$ & $\mathrm{N}$ & $\mathrm{N}$ & $\mathrm{N}$ & $\mathrm{N}$ & $\mathrm{N}$ & $\mathrm{N}$ \\
\hline Cup/disc & $\mathrm{N}$ & $\mathrm{N}$ & $\mathrm{N}$ & 0.9 & $\mathrm{~N}$ & 0.9 & $\mathrm{~N}$ & $\mathrm{~N}$ & $\mathrm{~N}$ & $\mathrm{~N}$ & $\mathrm{~N}$ & $\mathrm{~N}$ \\
\hline Vitreous liquefaction & + & + & $t^{a}$ & $t^{a}$ & $t^{a}$ & $t^{a}$ & $t^{a}$ & $t^{a}$ & $t^{a}$ & $t^{a}$ & $t^{a}$ & $t^{a}$ \\
\hline
\end{tabular}

$\mathrm{P}$, perception; HM, hand motion; IM, inferomedially; I, inferiorly; SM, superomedially; C, central; N, normal; A/E, atrophic and excavated optic disc.

${ }^{a}$ Presenile.

\section{Case 2 (Fig. 1, III-6)}

This 19-year-old white man was the younger brother of case 1 . He was the sixth child of his parents and had had myopia for 3 years. There was no past history of any medication. The best corrected visual acuity with a $-7.5 \mathrm{D}$ sphere was $6 / 10$ in the right eye and hand motion in the left eye. He had an exodeviation of 40 prism dioptres in the left eye. The corneas were clear with an estimated size of $11.6 \mathrm{~mm}$ horizontally in both eyes. Iridophacodonesis was present bilaterally and the pupils were in a central position. Presenile vitreous
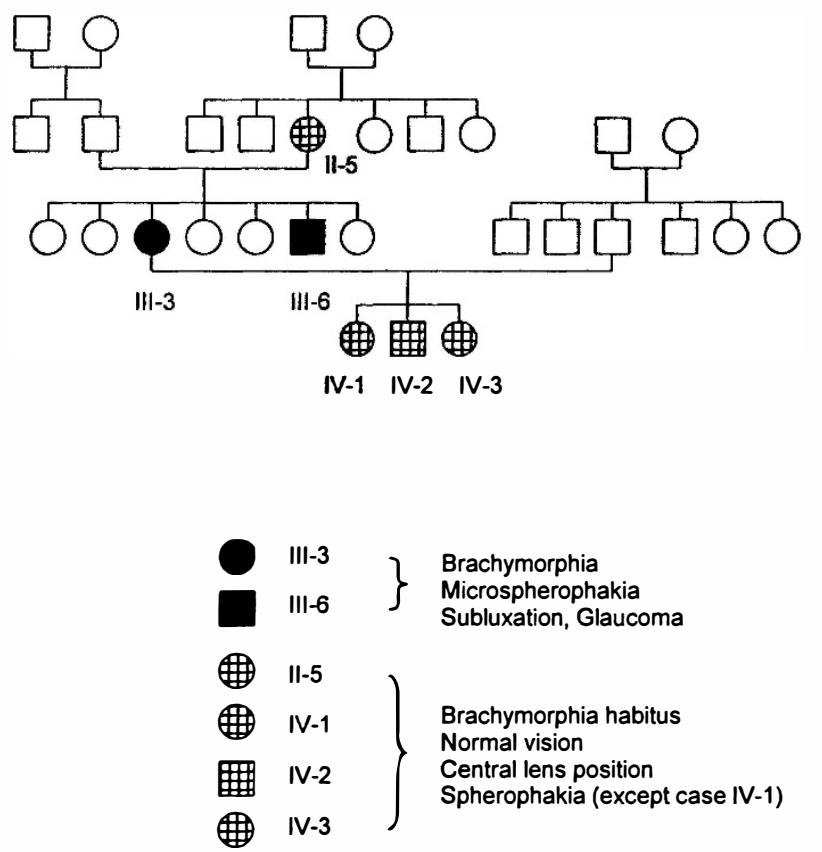

Fig. 1. Pedigree of the family with Weill-Marchesani syndrome in three generations. liquefaction was present in both eyes. The IOPs by applanation in the right and left eye were 18 and 41 $\mathrm{mmHg}$ respectively in the morning. Perimetry was normal in the right eye. The gonioscopic findings were the same as in his sister. Both lenses were microspherophakic, and subluxated inferiorly in the right eye and superomedially in the left eye (Fig. 2). The left cup-to-disc ratio was 0.9 , like that of his elder sister.

The patient was $152 \mathrm{~cm}$ tall (Fig. 3a) (<3rd percentile) with a weight of $52 \mathrm{~kg}$ ( $3 \mathrm{rd}$ percentile). His face was in a stiff attitude. He had the same dysmorphism with short hands and stubby fingers (Fig. 3b) as his sister. His fingers could not be fully extended or made into a fist. Radiographic and orthopaedic findings were also the same as his sister except that flexion and extension defects were prominent $\left(20^{\circ}\right.$ and $35^{\circ}$ respectively) at the wrists. General examination was otherwise within the normal limits.

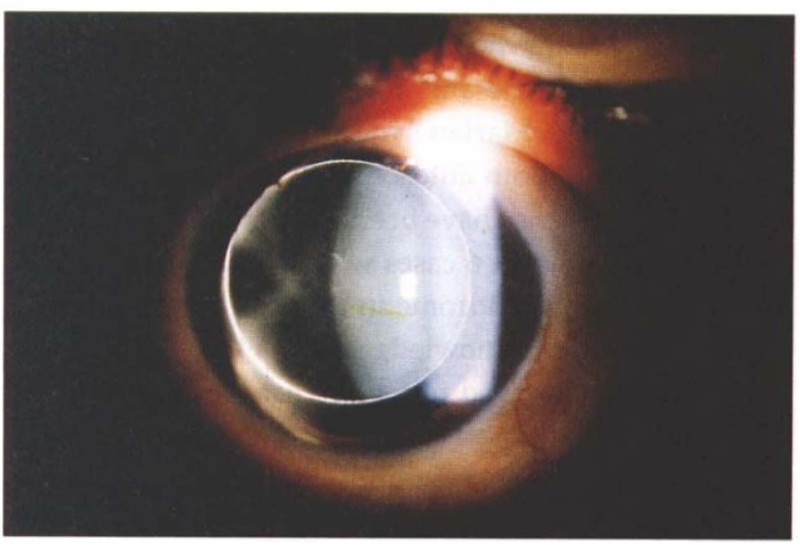

Fig. 2. Case III-6. Left eye showing microspherophakia with superomedial subluxation. 


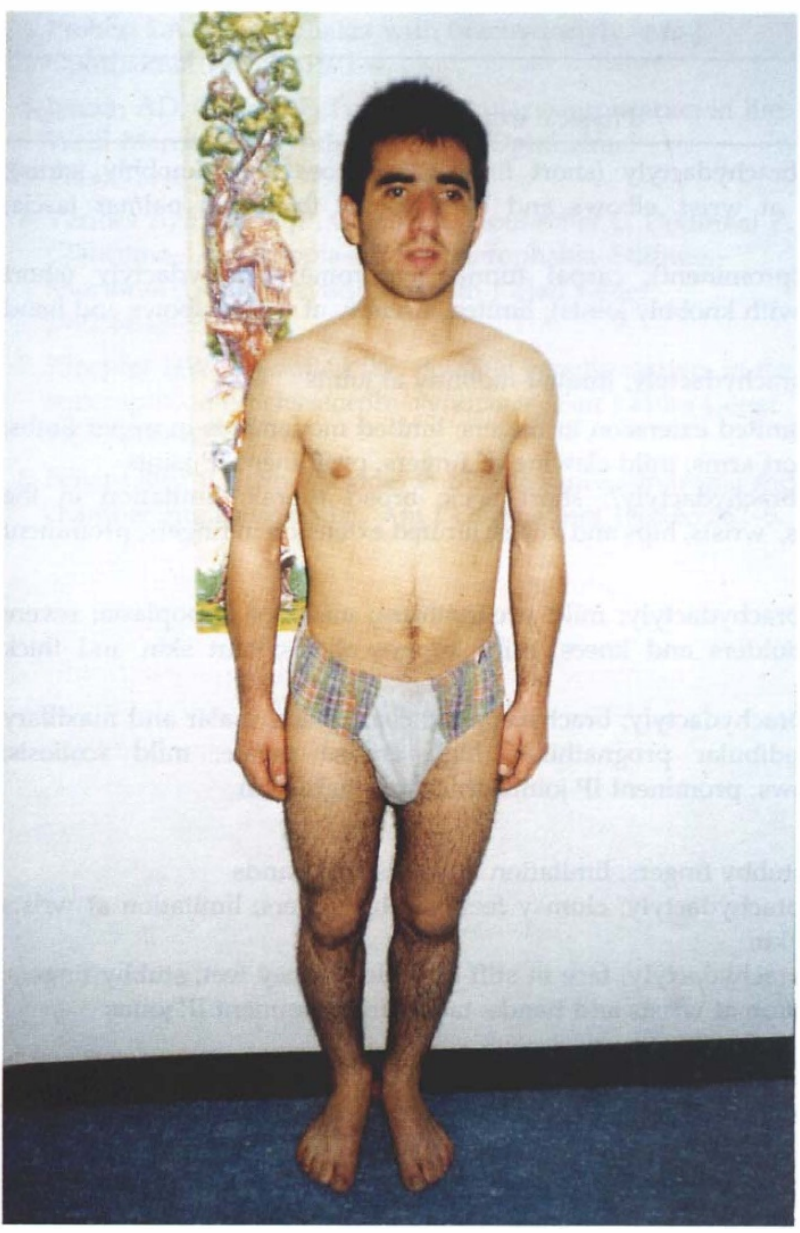

(a)

Cases 3 to 6 (Fig. 1, II-5, IV-1 to -3)

All these patients were brachymorphic with stubby fingers. All lenses were in a central position. Spherophakia were detected in cases 3 (II-5), 5 (IV-2) and 6 (IV-3). In all children, bilateral presenile vitreous liquefaction was detected. Articular restriction in case 3 was the same as in case 1 . General examinations were normal in other members of the family.

\section{Discussion}

Weill-Marchesani syndrome consists of short stature (present in $90 \%$ of cases), brachydactyly with stiff joints, progressive microspherophakia, progressive lens myopia, secondary glaucoma and ectopia lentis, usually downward. ${ }^{7}$ The angle becomes narrow because of the shallow anterior chamber caused by spherophakia and forward movement of the lens, although there are some cases of congenital angular abnormalities. ${ }^{8}$ Other reported anomalies are megalocornea, microcornea, scleral staphyloma, mesodermal dysgenesis of the anterior chamber, non-specific chorioretinal degeneration and primary osteoporosis. ${ }^{5,9}$ None of these findings was present in our patients except that of anterior chamber anomalies which may impede the aqueous flow.

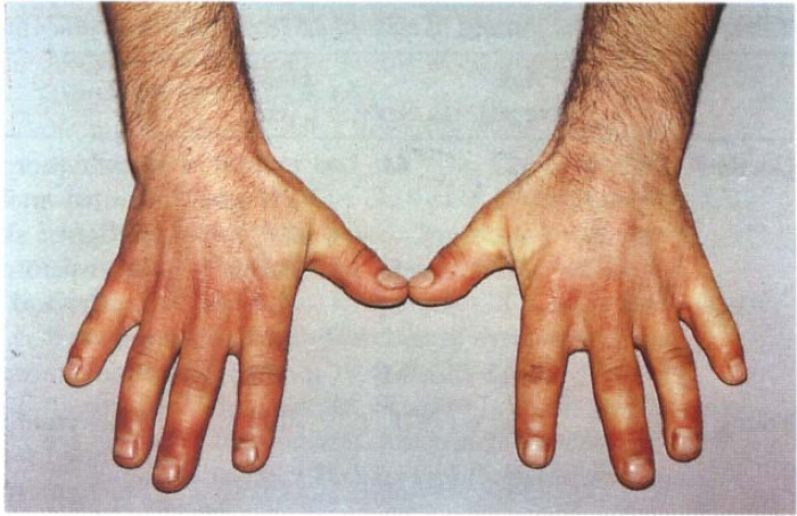

(b)

Fig. 3. (a) Case III-6. Aged 19 years with a stiff attitude of the face. (b) Short hands and stubby fingers.

The transmission of Weill-Marchesani syndrome has been reported as both autosomal recessive and autosomal dominant. ${ }^{4-70}$ Brachydactyly, short stature and significant refractive error noted among parents and other relatives suggest that the gene may be dominant with severely reduced penetrance and a wide range of expressivity (Table 2). ${ }^{2,4,5,7}$ Alternatively, the syndrome may be considered incompletely recessive with partial expression in the heterozygote. ${ }^{5}$ GEMSS syndrome (Glaucoma, Ectopia, Microspherophakia, Stiff joints, Short stature) was suggested as an acceptable name for the autosomal dominant form. ${ }^{6}$ However, the relationship between dominant and recessive Weill-Marchesani syndrome is not known. Most familial data on Weill-Marchesani syndrome, and the frequent consanguinity between the parents, support the model of autosomal recessive inheritance, but heterozygous patients may have short stature or brachydactyly, and may suffer refractive errors without ectopia. Our patients III-3 and III-6 have a typical dominant Weill-Marchesani phenotype and patients IV-1 to IV-3, though quite young, have short stature like their grandmother (II-5). As a consequence, apparent disparity between dominant and recessive Weill-Marchesani syndrome is ascertained through lens luxation (ectopia lentis).

The axial length measurements were totally asymmetric in 4 cases (II-3, III-6, IV-2, IV-3). Asymmetric glaucomatous damage was present in cases III-3 and III-6. Their relatively 


\begin{tabular}{|c|c|c|c|c|}
\hline & $\begin{array}{l}\text { Age } \\
\text { (years) }\end{array}$ & Sex & $\begin{array}{l}\text { Height } \\
(\mathrm{cm})\end{array}$ & Physical examination \\
\hline \multirow[t]{3}{*}{ Gorlin et al. ${ }^{13}$} & 42 & M & 150 & $\begin{array}{l}\text { Brachymorphy; brachydactyly (short fingers and toes with knobbly joints); } \\
\text { limited mobility at wrist, elbows and hand joints; thickened palmar fascia; } \\
\text { puckered skin }\end{array}$ \\
\hline & 9.5 & F & 104.5 & $\begin{array}{l}\text { Brachymorphy (prominent); carpal tunnel syndrome; brachydactyly (short } \\
\text { fingers and toes with knobbly joints); limited mobility at wrist, elbows and hand } \\
\text { joints }\end{array}$ \\
\hline & $13 / 12$ & M & 73.5 & Brachymorphy; brachydactyly; limited mobility at joints \\
\hline \multirow[t]{2}{*}{ Young et al. ${ }^{10}$} & 65 & $\mathrm{~F}$ & 145 & $\begin{array}{l}\text { Brachymorphy; limited extension in fingers; limited movements in upper limbs; } \\
\text { rounded face; short arms; mild clawing of fingers; prominent IP joints }\end{array}$ \\
\hline & 34 & M & 151 & $\begin{array}{l}\text { Brachymorphy; brachydactyly?; short neck; broad thorax; limitation in the } \\
\text { shoulders, elbows, wrists, hips and knees; limited extension in fingers; prominent } \\
\text { MP and IP joints }\end{array}$ \\
\hline \multirow[t]{3}{*}{ Verloes et al. ${ }^{6}$} & 58 & M & 169 & $\begin{array}{l}\text { Brachymorphy; brachydactyly; mild prognathism; mid-face hypoplasia; severe } \\
\text { limitation at shoulders and knees; mild kyphoscoliosis; taut skin and thick } \\
\text { skinfolds }\end{array}$ \\
\hline & 28 & $\mathrm{~F}$ & 159 & $\begin{array}{l}\text { Brachymorphy; brachydactyly; brachycephaly; coarse face; malar and maxillary } \\
\text { hypoplasia; mandibular prognathism; high arched palate; mild scoliosis; } \\
\text { limitation at elbows; prominent IP joints; thick and tight skin }\end{array}$ \\
\hline & 4 & M & ? & Unremarkable \\
\hline \multirow[t]{6}{*}{ Present study } & 65 & $\mathrm{~F}$ & 141 & Brachymorphy; stubby fingers; limitation at wrists and hands \\
\hline & 27 & $\mathrm{~F}$ & 144 & $\begin{array}{l}\text { Brachymorphy; brachydactyly; clumsy feet; stubby fingers; limitation at wrists } \\
\text { and hands; taut skin }\end{array}$ \\
\hline & 19 & M & 152 & $\begin{array}{l}\text { Brachymorphy; brachydactyly; face in stiff attitude; clumsy feet; stubby fingers; } \\
\text { prominent limitation at wrists and hands; taut skin; prominent IP joints }\end{array}$ \\
\hline & 8 & $\mathrm{~F}$ & 110 & Brachymorphy; stubby fingers \\
\hline & 5 & M & 98 & Brachymorphy; stubby fingers; spherophakia \\
\hline & 3 & $\mathrm{~F}$ & 85 & Brachymorphy; stubby fingers; spherophakia \\
\hline
\end{tabular}

MP, metacarpophalangeal; IP, interphalangeal.

longer left fundi showed deep excavated and atrophic papillae (C/D ratio: 0.9$)$. On the other hand, the shorter right fundi were normal in colour and appearance. The left IOPs were 19 and $41 \mathrm{mmHg}$, respectively. These values were 35 and $18 \mathrm{mmHg}$ respectively in the fellow eyes. However, the axial length of the eyes was an average of 1.3 $\mathrm{mm}$ longer than that of the right eyes in both cases. Chen $e t$ al. ${ }^{11}$ found that glaucoma patients have a longer axial length than people without glaucoma, especially in the younger age groups. We think that axially longer eyes in Weill-Marchesani syndrome should be followed closely in preventive medicine.

Weill-Marchesani syndrome was diagnosed by systemic findings in case IV-1. Spherophakia is not necessarily associated with the syndrome ${ }^{12}$ as was supposed by Marchesani and other investigators. In a previously reported study, reduced visual acuity was first noted at the age of 7.5 years on the average. In another study, significant myopia was noted at the age of 11.2 years with the diagnosis of lens subluxation at 18.2 years. ${ }^{5}$ Probert ${ }^{4}$ reported 3 patients who developed ectopia lentis between the ages 12 and 20 years. To our knowledge, congenital microspherophakia has not been reported in this syndrome, but it almost occurs.

Microspherophakia is apparently present prior to dislocation of the lens. The actual age at which subluxation develops can not be determined more precisely without serial examination. Therefore, in our children, the lenses originally found in the central position will probably become displaced in the future.
These cases appear particularly interesting as the patients also had vitreous liquefaction (presenile in the third and fourth generations) which, until now, has not been considered a possible manifestation of Weill-Marchesani syndrome. In order to make a diagnosis and to prevent potentially life-threatening systemic complications, early differential diagnosis is mandatory, especially in subtle cases for prognostic, therapeutic and genetic reasons (genetic counselling).

In conclusion, we present a family with 6 affected individuals in three generations, showing an autosomal dominant pattern. Vitreous liquefaction was present in all cases. Weill-Marchesani syndrome was full-blown in cases III- 3 and III- 6 . In both cases the patients presented first with unilateral total left glaucomatous optic atrophy in their axially longer eyes. This finding, as well as vitreous liquefaction, might alert the physician to an early diagnosis in preventive medicine. In these cases, the intraocular pressure and visual field must be carefully monitored. More families are needed to provide more details and an exact evaluation of this syndrome.

\section{References}

1. Weill G. Ectopia des crystallins et malformations générales. Ann Oculist 1932;169:21-44.

2. Marchesani O. Brachydactylie und angeborene Kugelllinse als Systemerkrankung. Klin Monatsbl Augenheilkd 1939;103:392-406.

3. Cross HE, Jensen AD. Ocular manifestations in the Marfan syndrome and homocystinuria. Am J Ophthalmol 1973;75:405-20. 
4. Probert LA. Spherophakia with brachydactyly. Am J Ophthalmol 1953;36:1571-4.

5. Jensen AD, Cross HE, Paton D. Ocular complication in the Weill-Marchesani syndrome. Am J Ophthalmol 1974;77:261-9.

6. Verloes A, Hermia JP, Galand A, Koulischer L, Dodinval P. Glaucoma-Lens ectopia-Microspherophakia-StiffnessShortness (GEMSS) syndrome. Am J Med Genet 1992;44:48-51.

7. Kloepfer HW, Rosenthal JW. Possible genetic carriers in the spherophakia-brachymorphy syndrome. Am J Hum Genet 1955;7:398-425.

8. Feiler-Obry V, Stein R, Godei V. Marchesani's syndrome and chamber angle anomalies. Am J Ophthalmol 1968;65:862-6.
9. Giordano N, Senesi M, Battisi E, Mattii G, Gennari C. WeillMarchesani syndrome: report of an unusual case. Calcif Tissue Int 1997;60:358-60.

10. Young ID, Fielder AR, Casey TA. Weill-Marchesani syndrome in mother and son. Clin Genet 1986;30:475-80.

11. Chen YF, Wang TH, Lin LL, Hung PT. Influence of axial length on visual field defects in primary open-angle glaucoma. J Formos Med Assoc 1997;12:968-71.

12. Dietlen TS, Jacobi PC, Krieglstein GK. Ciliary body is not hyperplastic in Weill-Marchesani syndrome. Acta Ophthalmol (Copenh) 1998;76:623-4.

13. Gorlin RJ, L'Heureux RR, Shapiro I. Weill-Marchesani syndrome in two generations: genetic heterogeneity or pseudodominance? J Pediatr Ophthalmol Strabismus 1974;11:139-44. 